\title{
Planning and Practice of Innovation and Entrepreneurship Curriculum Based on Innovative Ability Training
}

\author{
Yang Yongfu ${ }^{1, a}$ and Su Xiaoyan ${ }^{2, b^{*}}$ \\ ${ }^{1}$ No. 75 Xiuling road, Nanning city, Guangxi province, China. \\ ${ }^{2}$ No. 75 Xiuling road, Nanning city, Guangxi province, China. \\ a58501568@qq.com, b370233293@qq.com \\ * The Corresponding Author
}

Keywords: Innovation and entrepreneurship; Curriculum planning; Standard; Inovative ability

\begin{abstract}
We plan the innovation and entrepreneurship education curriculum system through the research and practice of the applied innovation and entrepreneurship education for university students. According to the national requirements for the innovation and entrepreneurship education, we research and analyze the current situation of innovation and entrepreneurship education curriculum at home and abroad, thus we can plan the innovation and entrepreneurship education curriculum system, and put it into practice from standardizing the curriculum system, building the applied innovative-technology and practical courses as well as the extension curriculum. From the theoretical knowledge, practice and knowledge structure of innovation and entrepreneurship, we should systematically educate and train college students in order to improve their innovative ability and sense of entrepreneurship and thus enhance their competitiveness. Planning of innovation and entrepreneurship curriculum based on innovative ability training is the requirement of national development, the requirement of national progress, the requirement of the transformation and development of higher education, and the vital task of the development of innovation and entrepreneurship education.
\end{abstract}

\section{The Background of the Curriculum Planning for the Innovation and Entrepreneurship Education}

The Guiding Ideology of the Curriculum Planning for the Innovation and Entrepreneurship Curriculum. We must fully implement party's education policies, answer the call of "Widespread Entrepreneurship and Innovation", carry out the basic task of strengthening morality and adhere to the "Comprehensive Application Orientation", we should also establish ourselves in regional economic and social development so as to vigorously promote the reform of the innovation and entrepreneurship education. Furthermore, we have to deepen the reform and implement the innovation-driven education reform and development strategy, insist on cultivating the innovative ability as the core. Let the innovation lead the entrepreneurship and let the entrepreneurship push forward the employment, in this case can we energetically launch the innovative quality education and foster the practical personnel with the innovative and entrepreneurial awareness and ability. Also, the medium and long-term development plan of the innovation and entrepreneurship education should be rationally mapped out, the effective mode of the innovation and entrepreneurship education must be actively explored, and the innovation and entrepreneurship curriculum system must be planned as a whole. Besides that, we have to improve and perfect the teaching conditions and policy guarantee, integrate the resources, create the conditions, perfect the mechanism, deepen the service, move forward the coordinated education between school and school, between school and enterprise, between school and the international school, promote the reform of the innovation and entrepreneurship education, fasten the training of the large-scale, great-innovative-spirit, strong-practical-ability innovative and entrepreneurial talents so as to boost the quality of the innovative, technical and practical talents, to deliver the innovative talents for the sake of establishing the innovative country as well as realizing "The Two Centennial Goals" and the Chinese dream, a great revitalization of the Chinese nation. 
The Rising of the Innovation and Entrepreneurship Education. "The earliest entrepreneurial courses could be dated back to Management of New Enterprises by Professor Myers Maes of the Harvard Business School in 1947, Entrepreneurial Spirit and Innovation by Peter Drucker of the New York University in 1952.[1]" Later, Stanford University and Massachusetts Institute of Technology set up the modern MBA entrepreneurial courses, concentrating on creating wealth and establishing enterprises. In 1968, Babson College took the initiative to set up entrepreneurial orientations in the Undergraduate Education, which opens up a new field of the innovation and entrepreneurship education in universities. In 1971, University of South California was the first to found MBA Entrepreneurship major, and then it created entrepreneurial orientation for the undergraduate next year. By the end of 1975, as many as 104 colleges and universities had provided entrepreneurship education courses in the United States.

"The innovation and entrepreneurship education of Chinese colleges and universities is initiated by Tsinghua University. At the initial stage of exploration, the government departments such as the Central Committee of the Communist Youth League, the Ministry of education and the Ministry of personnel protection form the pattern of symbiotic development of College Students' entrepreneurship competitions, entrepreneurship courses, entrepreneurship training and entrepreneurial societies.[2]" Based on "Quality Engineering", the Ministry of Education set up 32 innovative and experimental areas of the innovation and entrepreneurship education talents training mode in colleges and universities, and explored the promotion of entrepreneurship education and the cultivation of entrepreneurial talents in Chinese universities. Opinions on Promoting Innovation and Entrepreneurship Education and Independent Entrepreneurship of College Students, issued by the Ministry of Education in May 4, 2010, is a summary and promotion of the 8-year pilot education in colleges and universities, which is also a new starting point for the development of innovation and entrepreneurship education in colleges and universities. In June 14, 2013, the Ministry of Education, aiming at the innovation and entrepreneurship education as well as independent entrepreneurial work for college students, held a video conference to sum up the experience of innovation and entrepreneurship education in colleges and universities and the experience of independent entrepreneurship, to check the implementation of Basic Requirements for the Teaching of Entrepreneurship Education in Ordinary Undergraduate Schools, to give impetus to the overall improvement of the quality of innovation and entrepreneurship education in colleges and universities, and to promote more college students to start their own business. "In May 2015, the General Office of the State Council issued Implementation of the Views on Deepening the Innovation and Entrepreneurship Education Reform (SCS [2015] No. 36) and stressed, deepening the reform of innovation and entrepreneurship education in universities is an urgent need for the implementation of the innovation driven development strategy and the upgrading of economic quality and efficiency. It is also an important measure to promote the comprehensive reform of higher education and improve the college graduates' employment with higher quality.[3]" In 2016, the Ministry of Education identified 99 universities like Tsinghua University as the demonstration universities to deepen innovation and entrepreneurship education reform, and further guide and promote innovation and entrepreneurship education in colleges and universities.

Effective Implementation of Innovation and Entrepreneurship Curriculum. In order to fully implement the important deployment of the party and the country about the training of innovative and entrepreneurial talents, Tsinghua University, Beijing Institute of Technology, Nanjing University of Science and Technology, Guangxi University and many other universities have formulated a reform-deepening and implementation plan for innovation and entrepreneurship education, which has clarified talent training objectives, educational ideas and implementation principles in accordance with innovation and entrepreneurship education development, has set up the overall goal of innovation and entrepreneurship education reform, has refined the construction ideas to meet the needs of transformation and development, has carried out the main tasks and measures for the transformation and development to ensure the effective implementation of the curriculum planning for innovation and entrepreneurship and the normal development of teaching, 
from the aspects of the guiding ideology, the overall goal, the construction idea, the main tasks and measures, etc.

The Continuous Improvement of Innovation and Entrepreneurship Curriculum. As a rising star in the education industry, innovation and entrepreneurship education curriculum is under improvement with the education reform and social needs. There are some criticisms of the innovation and entrepreneurship education courses, and it is considered that these courses have shortcomings in this and that way at present. But in fact, some of the problems are not caused by the curriculum itself, and the innovation and entrepreneurship education curriculum can only solve the problem that it can solve. Some problems do exist, but that is the problem of practice as well as development. From the standpoint of development, the existence of such a deficiency is completely normal. In order to solve these problems, the curriculum planning will become an inevitable choice. The curriculum planning of innovation and entrepreneurship education is to study and solve problems in education and practice, so as to improve the curriculum. So, it can be said that the curriculum planning of innovation and entrepreneurship is the process of continuing to improve the curriculum.

\section{The Present Situation of Innovation and Entrepreneurship Education at Home and Abroad}

The Present Situation of Innovation and Entrepreneurship Education at Home. The first domestic entrepreneurship program competition held by Tsinghua University in 1998 has opened the prelude to the innovation and entrepreneurship education in China's colleges and universities. Subsequently, the government attaches great importance to this kind of competitions and thus it vigorously advance the development of innovative and entrepreneurial education. In December 2015, the Ministry of Education issued Notice on doing a Good Job for the Employment of the 2016 National Ordinary College Graduates and required all colleges and universities set up innovative and entrepreneurial education courses, develop innovative and entrepreneurial education courses for all students, and incorporate the courses into credit management since 2016. "According to the statistics of the Ministry of Education, $82 \%$ of the universities in China have set up compulsory courses or elective courses for innovation and entrepreneurship up to October 2015, and the number of courses offering entrepreneurship education has increased by 14\% compared with that in 2014 . $[4]^{\prime}$

"Curriculum is the carrier of teaching activities, and it is the basic way to achieve the goal of education."'5] Curriculum construction is a core problem in the innovation and entrepreneurship education, but China has not yet formed a systematic innovation and entrepreneurship curriculum system, and there are many problems in education. First, the innovation and entrepreneurship courses haven't fully integrated with the specialized courses. The Chinese universities don't regard the innovation and entrepreneurship education as one part of the mainstream education system, not integrating the innovation and entrepreneurship education into the overall educational system, and thus, it becomes separated from the specialized education and discipline teaching. Second, the theoretical courses of the innovation and entrepreneurship education can't seamlessly connected with its practical courses. Some schools have set up relevant innovative entrepreneurship courses, but they are only isolated courses and do not connect with other courses.

The Present Situation of Innovation and Entrepreneurship Education at Abroad. The theory of innovation and entrepreneurship education originated from the western developed countries. In 1947, Harvard University took the lead in opening the earliest entrepreneurship education. In 1967, the first graduate education course was launched globally by Babson College in the United States. Up to 2005, about 1600 universities out of 2000 universities in the United States have offered more than 1600 entrepreneurship courses.[6]" The main characteristics of American college entrepreneurship curriculum are as follows:

American universities set up cross-specialty literacy courses, integrating the basic entrepreneurship courses with the specialized courses, thus strengthening students' literacy education. 
American universities set up the entrepreneurship courses alone, including the following four aspects, entrepreneurial awareness, entrepreneurial knowledge, entrepreneurial ability quality and entrepreneurial practice. This has formed a set of relatively scientific and perfect teaching and scientific research system for entrepreneurship education, thus ensuring the effectiveness of the training of innovative and entrepreneurial talents.

"Foreign universities pay more attention to the relevance of entrepreneurship education and entrepreneurial practice. According to the British Higher Education entrepreneurship survey, 64\% of the entrepreneurial education activities in British universities are carried out outside of the curriculum.[7]" The United States, Britain, South Korea and other countries have carried out practical activities mainly through the establishment of University Entrepreneurship centers or network platforms, which are closely linked with all sectors of society. It thus forms an ecological system of entrepreneurship education with good interaction among universities, communities and enterprises. The main activities of American College entrepreneurship centers are divided into the in-school and extension projects. The in-school projects refer to students carry out the activities of starting a business plan competition, internship, student club and so on in the school while the extension projects refer to the close relationship among schools, enterprises and communities, including the invitation of entrepreneurs to hold the school lectures, seminars, to cooperate with hi-tech industrial parks, business incubators and others.

\section{The Planning of Innovation and Entrepreneurship Education Curriculum}

Taking the training of innovative ability as the core, specialty as the base and training the applied innovative-technology talents as the goal, we can rationally plan the curriculum of innovation and entrepreneurship education. In the course of entrepreneurship curriculum planning, we should focus on the needs of innovation-driven entrepreneurship, and guide the students to use innovative thinking to carry out their entrepreneurial activities.

Standardization of Curriculum System. The actual situation of specialized teaching should be combined, and thus the innovation and entrepreneurship curriculum is integrated into the specialized training plan. The curriculum of innovation and entrepreneurship education can be divided into general compulsory courses and specialized elective courses. So, we should follow the progressive principle in the course of arranging the courses. The public required courses for innovation and entrepreneurship can be offered in the first academic year, teachers mainly impart the innovative and entrepreneurial knowledge. In the second and third academic years, teachers offer innovative and entrepreneurial elective courses, and pass on specialized innovative skills, entrepreneurial knowledge, entrepreneurial skills and entrepreneurial training to students with entrepreneurial intentions. Students can choose different-module courses to learn. The curriculum structure of innovation and entrepreneurship education is shown in Figure 1.

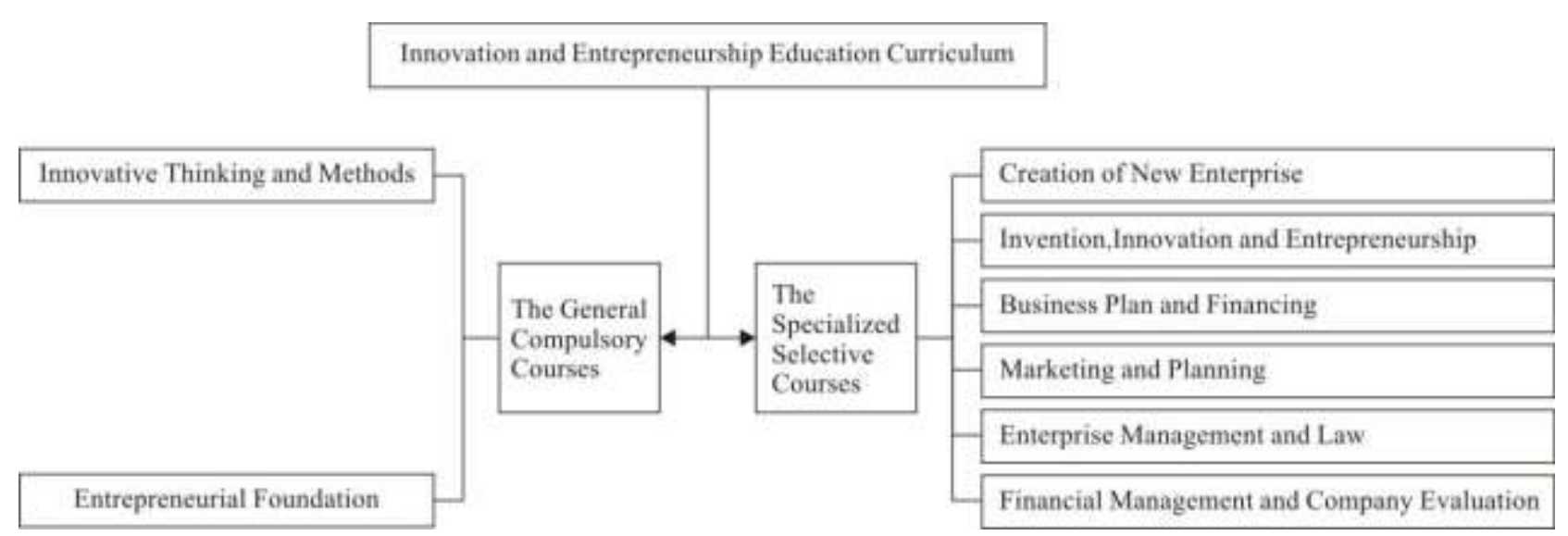

Figure 1. The Curriculum Structure of Innovation and Entrepreneurship Education 
Building of the Applied Innovative-Technology Practical Curriculum. The practical course is an important part of the innovation and entrepreneurship curriculum. The practical course mainly concentrates on the centralized comprehensive-design practical training and the practice course of team-based innovation and entrepreneurship project. Through these two practical courses, we can cultivate students' innovative thinking, innovation practice and entrepreneurial ability, to form a comprehensive knowledge structure and ability structure.

To carry out comprehensive-design innovation experimental and training activities. The proportion of the experimental training courses is above $30 \%$, with the emphasis on running innovative and comprehensive experimental training. Under the guidance of teachers, students are divided into several teams. In the way of simulating project design or actual project design, innovative experiments are carried out in open laboratories to get direct experience of innovative design. After investigation of the experimental and training teaching in the independent colleges, $72 \%$ of the students are more interested in innovative and comprehensive experimental training compared with the replication experiments. Through innovative experiments and training, students can further understand the requirements of enterprise product research and development, the rules and requirements of product innovation.

To carry out university students' maker activities. Maker space as the platform, innovation practical projects and entrepreneurial training projects as the support, schools adopt open and team-based management to orderly organize student teams to hold maker activities, such as, having product development, technological innovation, entrepreneurial module innovation, etc, which can stimulate students' motivation of innovation and entrepreneurship, and cultivate students' team cooperation, innovation practice and entrepreneurial ability. For example, Guangxi University Xingjian College of Science and Liberal Arts set up 40 maker rooms in 2017. 31 student-maker teams enter the maker space within one year. Each team matches 1 tutor, and each team owns more than 5 team members. By December 2017, the maker teams have completed 21 items, such as intelligent curtains, home intelligent housekeepers and others.

To carry out the regular entrepreneurship activities such as college students' independent entrepreneurial experience activities, entrepreneurship-themed lectures, entrepreneurship salons and other entrepreneurial activities. Schools should organize student teams to hold self-entrepreneurial experience activities in schools, let students explore the entrepreneurship knowledge on their own and understand the joy of entrepreneurship, at the same time, they can reflect on their shortcomings, which can lay the seeds for further improving entrepreneurship ability.

To carry out the innovative entrepreneurship practical training projects. The economic management comprehensive practical training center and other incubators as the base, the practical training projects as the carrier, such as simulated entrepreneurial projects or pre-entrepreneurial projects, students are encouraged to start business training in the incubators. In project positioning, we encourage technological innovation, profit innovation projects and other innovative ones, and guide student teams to improve their entrepreneurial plans through entrepreneurial training, and test them in incubators. Through the idea of innovation-driven entrepreneurship, we guide students to carry out entrepreneurial training activities, enable students to summarize successful experiences and failures in training, cultivate their persistence and pioneering spirit, and accumulate experience in project management and operation.

To carry out the activities of innovation and entrepreneurship competition. We should organize students to participate in the well-known provincial and national innovation and entrepreneurship competitions, such as the Challenge Cup Business Plan Competition, Internet Plus Innovation and Entrepreneurship Competition for College Students and National E-Commerce Creative and Innovative Entrepreneurship Challenge. During the competitions, students get valuable experience in entrepreneurship training, learn and accumulate entrepreneurial knowledge, exercise teamwork, interpersonal and organizational management capabilities, and improve research and analysis ability.

Energetically Promoting the Construction of the Extension Course. Strengthening innovation and entrepreneurial ability in school-enterprise cooperation and coordinated education. 
"School-enterprise cooperation and coordinated education are the important contents of the transformation and development of colleges and universities, which plays an important role in the production-study cooperation, the co-construction of specialty, the construction of the colleges and the demand for the employed and entrepreneurial talents.[8]" Colleges and universities can make use of their own conditions to create some stable practice places for innovative and entrepreneurial training, such as creating maker space, training center, incubator and so on. In the training and practice bases, students can accumulate practical experience, broaden their horizons, understand the composition, management and operation of enterprises, enhance the innovative and entrepreneurial ability so as to find entrepreneurial opportunities.

Creating an innovative and entrepreneurial atmosphere in the construction of campus culture. It is inseparable from the construction of campus culture to guide college students to correctly understand the innovation and entrepreneurship education and create a good atmosphere for innovation and entrepreneurship. "Therefore, we should make full use of the campus website, radio, newspaper, official micro-blog, display windows, panels and others to vigorously promote the significance and effectiveness of the innovation and entrepreneurship education, timely give publicity to the typical characters and events of the innovation and entrepreneurship spirit, awareness and ability, strive to form the spiritual and cultural environment of "dare to innovation, respect entrepreneurship, have the courage to take challenge, tolerance of failure" in campus, so that college students can correctly recognize and accept the culture of innovation and entrepreneurship.[9]"

Learning innovation and entrepreneurial knowledge in the network courses. With the growing up of Internet plus teaching, learning ways become more diverse, students use computer, mobile phone, tablet and other hardware to gain new knowledge in the Internet environment. Colleges can provide students with suitable innovation and entrepreneurship courses in some online-course websites, like ERYA, MYCOURSE and so on. Some universities can even build their own online curriculum platform, "set up innovative and entrepreneurial micro lesson libraries, interactive communication, virtual simulation training and other sections, guide and inspire college students' autonomous learning ability and innovation and entrepreneurship capabilities, providing a convenient platform for their personalized development.[10]"

\section{The Practice of Curriculum Planning for Innovation and Entrepreneurship Education}

Organizational Setup. The institute of innovation and entrepreneurship should be set up to coordinate the work of innovation and entrepreneurship education in the whole college. The institute of innovation and entrepreneurship is led by the main leaders of the college. The teaching and research department, the student work department, the personnel department, the finance department, the experimental teaching center and the other departments are jointly involved. The innovation and entrepreneurship committee has offices under the teaching and research department, and is responsible for the specific daily work. Taking personnel training as the fundamental task, and aiming at training students' awareness, spirit and ability of innovation and entrepreneurship, we should integrate government, school and enterprise resources to coordinately educate students, to systematically carry out innovation and entrepreneurship education, entrepreneurship training and practice, to open innovation experimental training courses, to organize innovation and entrepreneurship competitions at all levels. Furthermore, it is responsible for the application and management of the innovation and entrepreneurship projects for college students, in charge of the contact management of maker spaces and the innovation bases inside and outside the school; it is responsible for getting contact with academia and industry business mentors, holding students' innovation and entrepreneurship training, guiding students to start business, establishing innovation entrepreneurship association and holding innovation and entrepreneurship seminars as well as salons.

Building of Teaching Staff. We should pay attention to the training of a team of double-qualification tutors with great quality and a combination of full-time and part-time tutors. Based on the actual, we should fully tap the potential of existing teachers and gradually establish a 
suitable teacher team through training, introduction and transfer, etc. Also, we support teachers to have practical activities in enterprises and institutions, encourage teachers to carry out innovation and entrepreneurship projects of enterprises and institutions, to guide teachers to actively learn innovation and entrepreneurship education theory, so that teachers' innovative entrepreneurship education theory and practice ability can be constantly improved.

We actively invite successful entrepreneurs, experts, scholars and other related professionals to form a team of part-time tutors. By carrying out the innovation and entrepreneurship experience-exchanging meetings, symposia, seminars, lectures regularly held by the part-time tutor team, full-time teachers and students can summarize the experience of innovation and entrepreneurship education, and constantly improve the level of innovation and entrepreneurship practice.

We should set up a library of innovative and entrepreneurial tutors. The excellent tutors should be selected from the school teachers, successful entrepreneurs, experts and scholars. Then, we can grade and manage them according to the their resume and work experience. We should make full use of the resources of the tutors' library and guide the students to carry out innovative and entrepreneurial activities with the ratio of teachers and students to 1:5.

Construction of 3+1 Curriculum System. The "3+1" talent training mode refers to the combination of basic specialized training and vocational skills training, the combination of theoretical teaching and practical teaching, and the combination of in-school training and outside-school training. It's a new talent training mode that integrates production, teaching and research into one, and integrates teaching with practice. "3" means focusing on in-school teaching in the first three academic years, students should learn basic specialized knowledge while teachers conduct teaching by adopting the principle of "learning for practice" while "1" refers to students are sent to the front line of enterprises for internship or entrepreneurship practice, so that students could get professional skills and quality training, and effectively improve their innovative skills and entrepreneurial ability in the last academic year.

We should strengthen the construction of the curriculum system and set up the required courses, like Innovative Thinking and Methods and The Foundation of Entrepreneurship. As for the students who have the innovative and entrepreneurial willingness, school can carry out the elective courses of innovation and entrepreneurship module while the incubating environment and support guarantee are provided for the students' entrepreneurial teams.

The innovative and entrepreneurial practice is integrated into the talent training program and integrated into the credit system. Students take part in creative activities such as award-winning subject competitions, innovation practice projects and entrepreneurial practice, which can obtain certain credits. To ensure that the knowledge, ability and quality of the students' innovation and entrepreneurship reach the expected requirements, we can integrate the practice of innovation and entrepreneurship into the talent training program for overall planning.

Base Construction. The school-level innovation and entrepreneurship training base, which is based on the creation of maker space and business incubator, is established. It can provide professional and personalized innovation and entrepreneurial guidance for university students.

The innovation and entrepreneurship base for university students is established. We should make full use of the training base outside the school and build a cooperative innovation center, which can provide more innovative practice and entrepreneurial training opportunities for students.

School should open and share the teaching resources, such as the laboratory. We should actively create the environment and conditions for innovation and entrepreneurship, which open to students free of charge, and provide equipment and facilities environment and technical support for the students' innovation and entrepreneurship project tests.

Cultural Construction. School should establish university innovation and entrepreneurship education visual identification system, standardize innovative and entrepreneurial image of education, extensively give publicity to the innovation and entrepreneurship education, create a good cultural atmosphere of innovation and entrepreneurship education.

Through the website, campus radio, official micro-blog and other media, schools actively 
promote the innovation policy, measures of state and local governments, to promote the publicity of innovation and entrepreneurship, to stimulate students' innovation and entrepreneurial enthusiasm, guide students to establish a scientific concept of entrepreneurship, of employment and of talent.

Schools create the cultural atmosphere of innovation and entrepreneurship in the boards, display windows of the classroom, laboratory, library, maker spaces and incubation centers, let students recognize and accept the cultural education of innovation and entrepreneurship.

Guarantee Mechanism. System guarantee. The systematic policy of innovation and entrepreneurship education management, teaching and examination has been published, so that innovation and entrepreneurship education can be regulated, and it provides system guarantee for the construction of innovation and entrepreneurship courses, which ensures that students' innovation and entrepreneurship learning and practice can be carried out smoothly.

Financial guarantee. The funds needed for innovation and entrepreneurship education are included in the annual budget to support, encourage and help the teaching guidance, use of places, funds, activities and so on. Meanwhile, In accordance with the relevant policies of the state and local governments, it provides help and support for students with willingness to apply for commercial loans or venture capital.

\section{Conclusion}

Developing innovation and entrepreneurship education is an important measure to implement the national strategy of "Widespread entrepreneurship and innovation". It is an opportunity for college education reform and a main way to promote the all-round development and employment of college students. In August 18, 2014, General Secretary Xi Jinping mentioned in the speech of the seventh meeting of the central financial leadership group: "talent is the foundation of innovation and the core element of innovation. Innovation driven is essentially talent driven. In order to accelerate the formation of a team of large-scale, innovative-spirit and dare-to-take-risks innovative talents, we should focus on making good use of, attracting and training the talents." Therefore, planning of the innovation and entrepreneurship curriculum system based on innovative ability training is the requirement of national development, the requirement of national progress, the requirement of the transformation and development of higher education, and the important task of the development of innovation and entrepreneurship education.

\section{Acknowledgement}

This paper is Funded by the Project of Innovative and Entrepreneurial Team Construction in Guangxi

\section{References}

[1] J.A Katz. The Chronology and Intellectual Trajectory of American Entrepreneurship Education : 1876-1999 [M]. Journal of Business Venturing

[2] Zhang Yuli, Li Zheng. The Rise and the Progress of Theoretical Research of University Entrepreneurship Education. Research and Practice of Entrepreneurship Education in the Era of Innovation [M]. Modern education press,2006,9.

[3] Suggestions on Deepening the Implementation of Innovation and Entrepreneurship Education Reform in Colleges and Universities [Z]. General Office of the State Council, 2015,36.

[4] Wang Zhanren. The History of Innovation and Entrepreneurship Education in China [M]. Social Sciences Publishing House, 2016,6.

[5] Zhang Yuangang. Research on the Curriculum System of Entrepreneurship Education in Colleges and Universities [J]. Journal of Huangshan University.2012.

[6] Li Bo. Research on Entrepreneurship Education in American Universities [D]. Jilin: School of Education, Northeast Normal University, 2008.

[7] Chen Wenhua. The Rise of Entrepreneurship Education in Colleges and Universities and 
Innovative Exploration in China [J]. Journal of Shenzhen Institute of Information Technology, 2016.12.

[8] Bai Rixia, Chen Xingwen, Fu Jie. Deepen the Practical Teaching Reform to Improve the Students' Ability of Entrepreneurship and Innovation [J]. Laboratory Research and Exploration, 2010.3 .

[9] Li Zuozhan. Design of University Entrepreneurship Education Curriculum Based on Quality and Ability [J]. China Electric Power Education, 2009.8.

[10]Zheng Ruilun. The Construction and Practice of the Curriculum System of Innovation and Entrepreneurship Education in Private Colleges and Universities. Journal of Southwestern Normal University: Natural Science Edition [J].2012. 